\title{
Accommodation Experience in the Sharing Economy: A Comparative Study of Airbnb Online Reviews
}

\author{
Zhihua Zhang ${ }^{1}$ and Rachel J. C. Fu ${ }^{2, *}$ \\ 1 Department of Civil and Environmental Engineering, The University of Tennessee, \\ Knoxville, TN 37996-2313, USA; zzhang78@vols.utk.edu \\ 2 The Eric Friedheim Tourism Institute and Department of Tourism, Hospitality and Event Management, \\ University of Florida, Gainesville, FL 32611-8209, USA \\ * Correspondence: racheljuichifu@ufl.edu
}

Received: 15 November 2020; Accepted: 11 December 2020; Published: 15 December 2020

check for updates

\begin{abstract}
Current research investigating the accommodation experience in the sharing economy in China is limited, especially from a cross-cultural perspective. To fill this gap, this study examined the accommodation experience of Airbnb guests using text-mining techniques and compared the accommodation experience perception between two culturally different groups: domestic Chinese and foreign English-speaking Airbnb guests. The results showed that the two groups shared eight common dimensions, including "Convenience/Location", "Amenities", "Feel at home", "Check-in/out", "Experience", "Availability/Transportation", "Host", and "Style/Decoration". However, there are differences in the relative importance of each dimension of accommodation experience between the domestic and foreign Airbnb guests. For example, the foreign guests more often mentioned homeliness, location/convenience, and availability/transportation, while the domestic guests showed greater interest in check-in procedures and style/decoration. Additionally, the two groups have several unique dimensions. The dimensions unique to foreign guests are "Recommendation" and "Booking flexibility", while the dimensions unique to domestic guests are "Revisit" and "Cleanliness". This study provides both theoretical and practical implications for peer-to-peer accommodation hosts and platforms. For example, Airbnb hosts can improve the satisfaction of Airbnb guests by improving several common extracted topics (e.g., amenities quality and host response) and the fact that foreign guests care more about homeliness, while domestic guests pay more attention to the check-in process and house design and decoration.
\end{abstract}

Keywords: sharing economy; Airbnb; online reviews; text mining; cross-culture

\section{Introduction}

The rapid growth of the sharing economy or collaborative consumption has rapidly changed the trends of consumers, which has sparked mounting interest from both academia and industry professionals. The sharing economy is a peer-to-peer activity that allows people to share or obtain goods and services, often through online platforms $[1,2]$. In the tourism and hospitality sector, Airbnb is a prominent example of peer-to-peer accommodation, enabling people to offer their unoccupied houses or rooms for short-term rental. As of 2019, Airbnb has served 500 million people with over 6 million Airbnb listings in more than 191 countries and regions [3]. Peer-to-peer accommodation platforms such as Airbnb have become an indispensable part of the tourism and hospitality industry.

Alongside the gaining popularity of peer-to-peer accommodation, much research has been undertaken. Recent studies have examined various topics on peer-to-peer accommodation such as its advantages and challenges [4-6] and questions of trust and reputation [7,8]. In addition, studies have also explored measuring the effects of peer-to-peer accommodation on the hotel industry $[9,10]$, 
identifying factors affecting price [2,11,12], and exploring geographic patterns [13,14]. However, limited, yet still growing, studies have been devoted to accommodation experiences in the sharing economy, although it has been commonly recognized that the growing popularity of peer-to-peer accommodation can be partly attributed to its providing guests with unique stay experiences through direct interactions with local communities [5].

Currently, there is little understanding of the accommodation experience in the sharing economy in China, especially from a cross-cultural perspective. To fill this gap, in our study we attempt to examine Airbnb guest's accommodation experience in terms of the hidden dimensions presented in online reviews (180,460 review comments from 28,452 Airbnb listings in Beijing, China). The specific objectives are (1) To identify the dominant topics in Airbnb accommodation experience presented in review texts for both domestic and foreign guests; and (2) To compare the extracted dimensions in Airbnb accommodation experience of domestic and foreign guests.

The rest of this study is organized as follows. Section 2 presents a review of the extant literature related to accommodation experiences in the sharing economy and user-generated content (UGC). In Section 3, we describe the data and methodology used in this article. Then, the main results are shown in Section 4, and the conclusions are presented in Section 5.

\section{Literature Review}

\subsection{Accommodation Experience in the Sharing Economy}

The rapid growth of peer-to-peer accommodation such as Airbnb can be partly attributed to its offering an alternative accommodation experience for guests. Peer-to-peer accommodation provides guests a local experience by enabling guests to interact with the hosts or neighbors. Moreover, peer-to-peer accommodation tends to be more scattered than conventional hotels, thus making it possible for the user to stay in a non-tourist area, or even a local area [5].

Many studies have explored people's accommodation experiences in the sharing economy, and among these studies, there are three main fruitful lines. The first line is identifying the dimensions/attributes of accommodation experience in the sharing economy [15-18]. Earlier studies have mainly used survey data or interview data to identify the dimensions/attributes that form the basis of or affect the accommodation experience. For example, [15] investigated Airbnb guests' perceptions of service quality and found that convenience and assurance are important service quality factors. Wang and Jeong [18] showed that amenities and the host-guest relationship could affect users' satisfaction with the Airbnb stay. More recent studies have started to analyze user-generated content (UGC) with text-mining techniques to explore accommodation experiences in the sharing economy. For example, Luo and Tang [17] identified five important aspects that impact accommodation satisfaction: communication, experience, location, product/service, and value. Cheng and Jin [16] found three key attributes ('location', 'amenities', and 'host') that affected Airbnb users' accommodation experiences, drawing from 181,263 Airbnb review comments in Sydney, Australia.

Examining the factors affecting accommodation experiences is another theme in the sharing economy research [19-23]. Factors such as authenticity, social interaction, location, and trust have been found to significantly affect guests' accommodation experiences in the sharing economy. For example, Sthapit and Jiménez-Barreto [19] interviewed twenty people who had positive Airbnb experiences and found that the positive accommodation experiences were significantly associated with the social interactions with the host, the attitude of the hosts, and the location of the accommodation.

The third line is comparing the accommodation experience in the sharing economy with other sectors such as hotels [24-27]. Several studies have found that there can be significant differences in accommodation experiences for peer-to-peer accommodation and hotels. For example, Belarmino, Whalen, Koh, and Bowen [25] investigated and compared the key attributes/dimensions of peer-to-peer accommodation and hotels with the guests' online reviews. It was found that the guests of peer-to-peer accommodation care more about interaction with hosts, and the guests of hotels care more about 
the hotel amenities. Additionally, Zhang, Cui, Cheng, Zhang, and Li [26] explored the guests' perceived differences between peer-to-peer accommodation such as Airbnb and hotels, and the key attributes identified of significant difference were pets, atmosphere, flexibility, value for money, and quality assurance.

To date, previous studies have mainly focused on Western tourists' accommodation experiences in the sharing economy; limited yet rising studies have investigated Eastern tourists' accommodation experiences, especially those of Chinese tourists [28,29]. China is one of the biggest markets for Airbnb, and Airbnb has said that China would be its largest market by 2020. Therefore, it is necessary to understand the customers' accommodation experiences in the sharing economy in China. To this end, this study aims to explore Airbnb guests' accommodation experiences in China and the similarities and differences in accommodation experience between domestic guests and foreign guests.

\subsection{User-Generated Content as a Resource for Accommodation Experience Research}

In past decades, the development of technology and social media has created a great deal of user-generated content (UGC) on a wide range of platforms like blogs, forums, and consumer review websites. UGC is commonly considered an important resource to unpack user experience that could deepen the understanding of user behavior and satisfaction both in academia and the tourism/hospitality industry.

Accommodation experience is one of the main topics in hospitality research that has received much attention. In particular, many studies used online consumer reviews, a type of evaluation of product or service created by consumers based on their personal experiences [30], as the primary data to investigate consumers' experience in accommodation experience research. Consumer reviews were always focused on a specialized topic and contained the customers' evaluation of products or services, which makes them an appropriate and reliable way to understand costumers' feelings and perceptions about their experiences [31]. For example, Zhou et al. [32] identified seventeen hotel attributes affecting customer satisfaction by analyzing online reviews from upscale hotels. Barreda and Bilgihan [33] found that travelers' online reviews contained both positive and negative hotel experiences and identified the main dimensions that motivate travelers to evaluate their hotel experiences.

In the sharing economy, a growing number of studies have also explored the accommodation experience with UGC. Brochado et al. [34] examined 1776 Airbnb web reviews in three nations, US, Portugal, and India, and tested the convergence of consumer experience using thematic analysis. Cheng and Jin [16] investigated the attributes affecting Airbnb users' experiences with a set of online review comments. Three attributes, "location", "amenities", and "host", were found to be the key influencers. With online reviews, Zhang, Cui, Cheng, Zhang, and Li [26] identified the key similarities and differences between peer-to-peer accommodation and hotels, such as the ability to bring pets, atmosphere, flexibility, and value for money.

Currently, few studies have investigated the impact of cultural dissimilarity on people's accommodation experiences in the sharing economy. Although previous studies have explored accommodation experiences with UGC, none of them are from a cross-cultural perspective. Moreover, culture was commonly recognized as an important factor affecting people's travel and accommodation experiences [35,36], which could play an important role in the development of the sharing economy, but it has yet not been deeply studied. Our study contributes to the literature by comparing the online reviews of two culturally different groups and the aspects they value in their accommodation experiences with text-mining techniques, especially the Latent Dirichlet Allocation (LDA) analysis, a common and useful method in topic modeling.

In this study, we argue that UGC offers great potential for understanding users' accommodation experiences in the sharing economy, particularly for foreign visitors. As the number of inbound tourists in China is growing, understanding the preferences of foreign visitors is becoming more and more important. Therefore, by analyzing millions of online reviews from Airbnb guests, our study sheds 
light on such matters and hence provides valuable insights into the preferences and differences of domestic and foreign visitors.

\section{Data and Methodology}

The Airbnb data for Beijing, China was obtained from Inside Airbnb website (http://insideairbnb. $\mathrm{com} /$ get-the-data.html), which provides open dataset about Airbnb listings and reviews. As of April 2019, we collected 180,452 review comments from 15,749 Airbnb listings in Beijing, China. Figure 1 displays the daily growth of the reviews. As shown, a clear and constant increasing pattern in reviews per day was observed from 2010 to 2019. In particular, the reviews per day have started to increase significantly since 2016, which may be due to the increasing acceptance of Airbnb in China. Additionally, we examined the language of all reviews and found that the top five frequent languages in our sample are Chinese (68.1\%), English (14.9\%), Korean (14.8\%), French (0.3\%), and Traditional Chinese $(0.2 \%)$, which account for about $98.3 \%$ of the total collected Airbnb reviews.

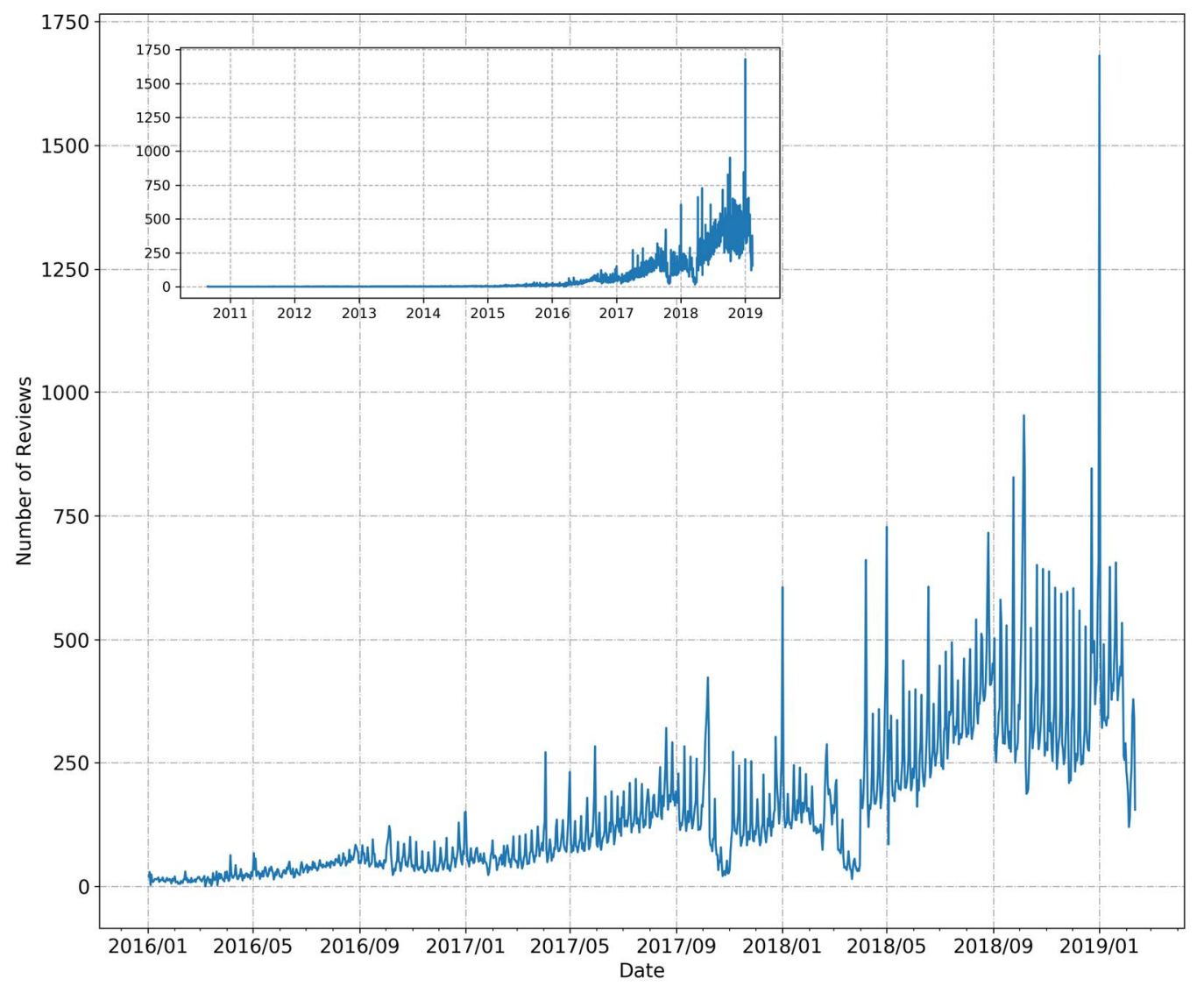

Figure 1. Number of Airbnb reviews by date.

In this study, we assumed that the Chinese reviews were written by domestic guests, and the English reviews were written by English-speaking foreign guests. To compare the Airbnb accommodation experience of foreign and domestic guests, we chose the 122,914 Chinese reviews and 26,280 English reviews to form the English and Chinese corpus.

First, text pre-processing was conducted before the Latent Dirichlet Allocation (LDA) analysis. Text pre-processing was done with several python modules (e.g., Natural Language Toolkit, Jieba), including text tokenization, word stemming, and stop words removing. Then, the LDA method was applied to extract the experiential dimensions of accommodation experience derived from Airbnb reviews.

LDA is a generative probabilistic model used for discovering the underlying topics in discrete data such as text documents [37]. It is the most commonly used method in topic modeling. The basic 
idea is that documents are represented as random mixtures over latent topics, where each topic is characterized by a distribution over words. For the LDA method, a set of terms is defined. It is assumed that a sequence of $N$ words constitutes a review, which is referred to as a "document" in the literature, $\boldsymbol{w}=\left\{w_{1}, w_{2}, \ldots, w_{N}\right\}$, whilst $M$ reviews form a corpus, $\boldsymbol{D}=\left\{\boldsymbol{w}_{1}, \boldsymbol{w}_{2}, \ldots, \boldsymbol{w}_{M}\right\}$. Additionally, we assume that there is $K$ number of dimensions across the corpus comprising all the $M$ reviews.

Based on the above definitions, LDA assumes the following generative process for each document $w$ in a corpus $D$, with $N_{d}$ words in each document $w$ using $K$ topics [37]:

1. Choose $N_{d} \sim \operatorname{Poisson}(\xi)$, where $N_{d}$ is the length of the document $d$;

2. Choose $\theta_{d} \sim \operatorname{Dir}(\alpha)$ for a document's topic distribution, where $\alpha$ is the $k$-vector parameter of the Dirichlet prior to the per-document topic distributions;

3. For each of the $N$ words $w_{n} \in\left\{1,2 \ldots, N_{d}\right\}$ for document $d$ :

- Choose a topic $z_{d, n} \sim \operatorname{Multinomial}\left(\theta_{d}\right)$;

- Choose a word $w_{d, n}$ from $p\left(w_{d, n} \mid z_{d, n}, \beta\right)$, a multinomial probability conditioned on the topic $z_{d, n}$, where $\beta$ is a parameter of the Dirichlet prior on the per-topic word distribution.

Based on Bayesian probability principle, we can compute the probability of a corpus by taking the product of the marginal probabilities of a single document:

$$
p(D \mid \alpha, \beta)=\prod_{d=1}^{M} \int p\left(\theta_{d} \mid \alpha\right)\left(\prod_{n=1}^{N_{d}} \sum_{z_{d, n}} p\left(z_{d, n} \mid \theta_{d}\right) p\left(w_{d, n} \mid z_{d, n}, \beta\right)\right) d \theta_{d}
$$

Following the abovementioned LDA process, we can extract the guests' most valued topics of accommodation experience in the sharing economy and the probability of each topic occurring in Airbnb online reviews.

\section{Results}

\subsection{Dimensions Extracted from Airbnb Reviews}

With the LDA method, we extracted the top ten dimensions (topics) of Airbnb accommodation experiences for both domestic and foreign guests. Within each topic, we also obtained the associated words and their relative weights. To name each dimension, we conducted the following process: first, one researcher named the dimension; then the second researcher confirmed the name. The name of the dimension was identified based on the logical connection between the most frequent words for a topic. For example, in Table 1, the topics "Amenities" and "Availability/public transportation" were identified based on the top 15 frequent words. For topic "Amenities", we got several keywords, like "water", "bathroom", "shower", and "kitchen", which are connected and can be generalized as topic "Amenities". Similarly, for the topic "Availability/transportation", the top frequency words like "convenient", "subway", "station", "transportation", and "walking" are related to the availability of public transportation. 
Table 1. An example of named dimension for both Chinese reviews and English reviews.

\begin{tabular}{cccc}
\hline \multicolumn{1}{c}{ Topic } & Relative Weight & Topic & Relative Weight \\
\hline \multicolumn{2}{c}{ Topic 1: Amenities } & Topic 2: Availability/public transportation \\
water & $1.6 \%$ & (convenient) & $5.9 \%$ \\
bathroom & $1.6 \%$ & (station) & $4.1 \%$ \\
room & $1.4 \%$ & (subway) & $2.6 \%$ \\
shower & $1.2 \%$ & (apartment) & $2.4 \%$ \\
apartment & $1.2 \%$ & (nearby) & $2.0 \%$ \\
kitchen & $1.1 \%$ & (downstairs) & $1.9 \%$ \\
toilet & $1.1 \%$ & (close) & $1.8 \%$ \\
floor & $0.9 \%$ & (house) & $1.7 \%$ \\
building & $0.8 \%$ & (location) & $1.7 \%$ \\
towel & $0.8 \%$ & (distance) & $1.5 \%$ \\
small & $0.7 \%$ & (room) & $1.4 \%$ \\
host & $0.7 \%$ & (transportation) & $1.4 \%$ \\
like & $0.7 \%$ & (grocery) & $1.4 \%$ \\
door & $0.6 \%$ & (minutes) & $1.4 \%$ \\
bedroom & $0.6 \%$ & (walking) & $1.2 \%$ \\
\hline
\end{tabular}

Tables 2 and 3 present the top ten dimensions (topics) and associated words extracted from Chinese reviews and English reviews, respectively. The ten extracted dimensions for English reviews are "Convenience/Location", "Amenities", "Feel at home", "Check-in/out", "Experience", "Availability/Transportation", "Host", "Style/Decoration", "Recommendation", and "Booking flexibility". Three dimensions ("Feel at home", "Experience", and "Recommendation") represent consumers' perception of his or her experience and the resulting response. Two dimensions ("Convenience/Location" and "Availability/Transportation") indicate consumer preference for the location and convenience of Airbnb listing; the remaining dimensions show the quality of Airbnb listings, including service quality and facility quality. Similarly, the ten extracted dimensions for Chinese reviews are "Convenience/Location", "Amenities", "Feel at home", "Check-in/out", "Experience", "Availability/Transportation", "Host", "Style/Decoration", "Revisit", and "Cleanliness". The foreign guests and domestic guests shared eight common dimensions in accommodation experiences in Airbnb.

Table 2. Extracted dimensions and associated words from English reviews.

\begin{tabular}{|c|c|}
\hline Dimension & Top 10 Words for Each Dimension \\
\hline Convenience/Location & place, Beijing, great, stay, location, good, city, close, nice, perfect \\
\hline Amenities & $\begin{array}{c}\text { water, bathroom, room, shower, apartment, kitchen, toilet, floor, } \\
\text { building, towels }\end{array}$ \\
\hline Feel at home & Beijing, home, stay, place, best, time, feel, apartment, like, great \\
\hline Check-in/out & check, host, late, airport, stay, arrive, time, night, early, good, helped \\
\hline Experience & house, Beijing, experience, nice, room, hutong, like, good, time, living \\
\hline Availability/Transportation & $\begin{array}{c}\text { subway, station, apartment, walk, close, restaurant, location, place, } \\
\text { convenient, metro }\end{array}$ \\
\hline Host & good, room, location, place, apartment, host, nice, Airbnb, great, English \\
\hline Style/Decoration & place, stay, flat, space, great, quiet, decoration, enjoy, cool, lovely \\
\hline Recommendation & $\begin{array}{l}\text { great, place, nice, stay, clean, location, amazing, helpful, } \\
\text { recommend, friendly }\end{array}$ \\
\hline Booking flexibility & $\begin{array}{c}\text { arrival, host, reservation, automated, cancel, posting, days, promise, } \\
\text { helpful, alarm }\end{array}$ \\
\hline
\end{tabular}


Table 3. Extracted dimensions and associated words from Chinese reviews.

\begin{tabular}{|c|c|}
\hline Dimension & Top 10 Words for Each Dimension \\
\hline Convenience/Location & $\begin{array}{l}\text { (Beijing), (alley), (convenient), (recommend), (travel), (attraction), } \\
\text { (forbidden city), (recommendation), (nearby), (Tiananmen Square) }\end{array}$ \\
\hline Amenities & $\begin{array}{l}\text { (room), (bathroom), (kitchen), (air conditioner), (living room), } \\
\text { (appliance), (towel), (toilet), (refrigerator), (washer) }\end{array}$ \\
\hline Feel at home & $\begin{array}{c}\text { (feeling), (homestay), (Beijing), (homeliness), (warm), (kids), (warm), } \\
\text { (home), (at home), (satisfaction) }\end{array}$ \\
\hline Check-in/out & $\begin{array}{c}\text { (host), (check-in), (problem), (solve), (time), (response), (early), (in time), } \\
\text { (communication), (contact) }\end{array}$ \\
\hline Experience & $\begin{array}{c}\text { (good), (room), (location), (clean), (cost-effective), (convenient), } \\
\text { (comfortable) (overall), (entire), (satisfaction) }\end{array}$ \\
\hline Availability/Transportation & $\begin{array}{c}\text { (convenient), (station), (subway), (apartment), (nearby), (downstairs), } \\
\text { (close), (house), (location), (distance) }\end{array}$ \\
\hline Host & $\begin{array}{c}\text { (host), (very), (dear), (lovely), (clean), (comfortable), (warm-hearted), } \\
\text { (aunt), (considerable), (like) }\end{array}$ \\
\hline Style/Decoration & $\begin{array}{c}\text { (like), (style), (decoration), (room), (suitable), (design), (house), (careful), } \\
\text { (happy), (arrangement) }\end{array}$ \\
\hline Revisit & $\begin{array}{c}\text { (next time), (Beijing), (host), (choose), (opportunity), (later), (stay), } \\
\text { (definitely), (revisit), (again) }\end{array}$ \\
\hline Cleanliness & $\begin{array}{c}\text { (host), (room), (clean), (experience), (house), (warm-hearted), (tidy), } \\
\text { (facility), (cozy), (satisfaction) }\end{array}$ \\
\hline
\end{tabular}

\subsection{Dimension Comparison between Domestic Guests and Foreign Guests}

Then, we compared the extracted dimensions from Airbnb English reviews with the dimensions extracted from Airbnb Chinese reviews. The common dimensions between Airbnb English and Chinese reviews are "Convenience/Location", "Amenities", "Feel at home", "Check-in/out", "Experience", "Availability/Transportation", "Host", and "Style/Decoration". These topics reflect common aspects that affect consumers' satisfaction with the accommodation experience. For example, a convenient location and easy transportation are important for both domestic and foreign guests.

However, the importance of each common dimension varies slightly between domestic and foreign guests. Figure 2 showed the comparison result of the relative importance of each dimension in terms of the practical frequency of the occurrence of each extracted dimension. As shown, for topics like "Amenities", "Host", and "Experience", foreign and domestic guests had similar mentions, since they are common yet important aspects of the accommodation experience. The foreign guests made greater mention of homeliness, location/convenience, and availability/transportation. This makes sense, since they will be in a significantly different and new environment, and they would like to choose Airbnb listings with convenient locations and easy transportation. They also care more about homeliness, since they want to have the feeling of being at home. Domestic guests more often mentioned check-in and checkout as well as style/decoration. This suggests that domestic guests are more likely to interact with Airbnb hosts about check-in issues. Additionally, domestic guests pay more attention to the details of Airbnb listings, especially the style and design.

In addition, several unique dimensions were found to be common to both Chinese reviews and English reviews. The dimensions unique to foreign guests are "Recommendation" and "Booking flexibility", while the dimensions unique to domestic guests are "Revisit" and "Cleanliness". The domestic guests tend to revisit, while the foreign guests would like to recommend. This makes sense, since it is easier for domestic guests to revisit. Foreign guests would like to have flexibility in booking, since their schedules may change easily. The domestic guests care about cleanliness, indicating their high expectations of Airbnb. 


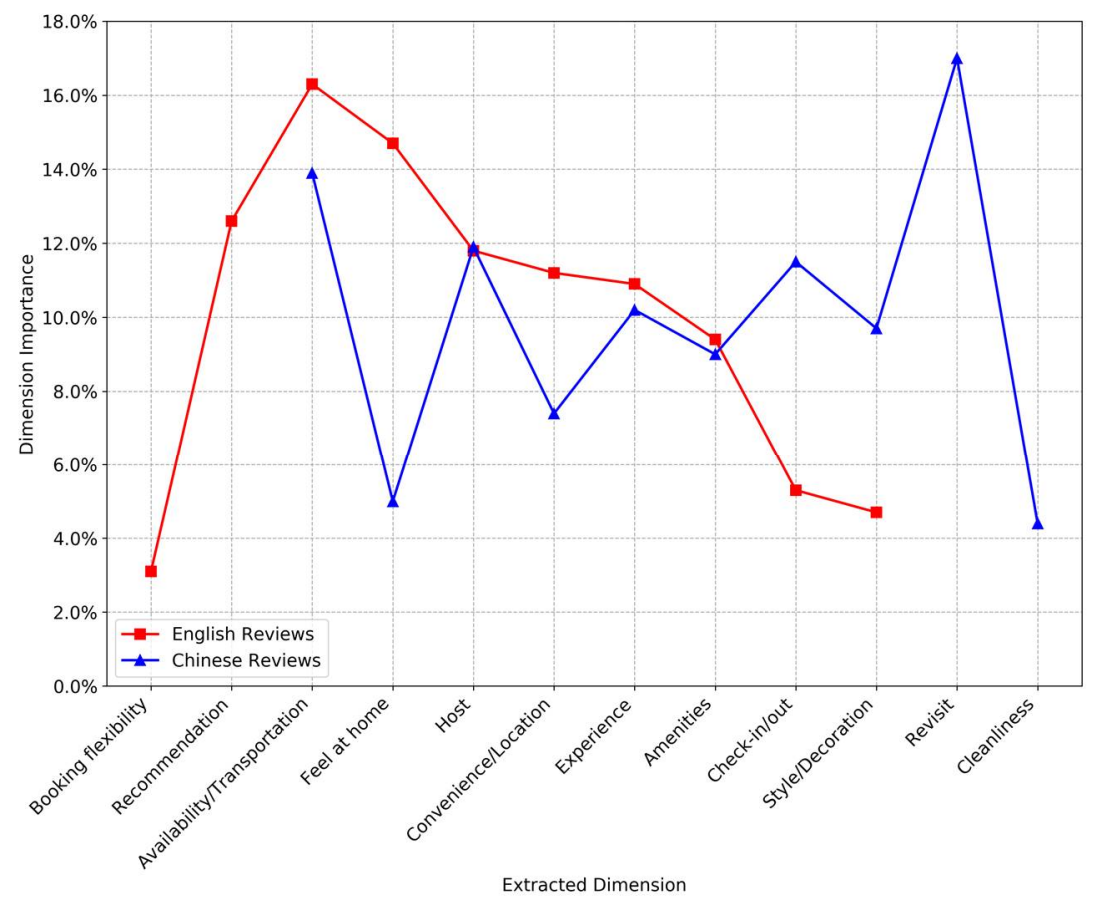

Figure 2. Comparison results of the relative importance of dimensions.

\section{Conclusions}

This study examined the accommodation experiences of guests on Airbnb using text-mining techniques (LDA method) and extracted latent topic dimensions from large but unstructured online reviews. Then, a cross-cultural comparative study was conducted between two culturally different groups, the domestic Chinese and foreign English-speaking guests. The results showed that the two groups shared eight common dimensions in accommodation experience, including "Convenience/Location", "Amenities", "Feel at home", "Check-in/out", "Experience", "Availability/Transportation", "Host", and "Style/Decoration". However, there were differences in the relative importance of each dimension of accommodation experience between the domestic and foreign Airbnb guests. For example, the foreign guests more often mentioned homeliness, location/convenience, and availability/transportation, while domestic guests more often mentioned check-in and style/decoration. In addition, the two groups have several unique dimensions. The dimensions unique to foreign guests are "Recommendation" and "Booking flexibility", while the dimensions unique to domestic guests are "Revisit" and "Cleanliness". In summary, there exists a subtle nuance between the accommodation experiences of domestic and foreign guests, and the cultural variable could be used to explain the difference.

The results of this study have both theoretical and practical implications. Theoretically, this study contributes to the literature by utilizing text mining techniques to examine the hidden features from online reviews and comparing experience perceptions between culturally different groups. In addition, this study extracted important dimensions of the accommodation experience in the sharing economy for two culturally different groups, and future research could investigate how consumer decisions in the sharing economy would be affected by these dimensions and how those influences differ among culturally different groups. Practically, this study can provide several implications for both Airbnb hosts and peer-to-peer accommodation platforms. First, this study helps Airbnb hosts better understand customers' accommodation needs, thus improving their competitiveness in the industry. For Airbnb hosts, the research findings suggest that Airbnb hosts can improve the satisfaction of Airbnb guests by improving several common extracted topics (e.g., amenities quality and host response). For example, Airbnb hosts should be responsive and provide a smooth check-in process for guests. The findings also reiterate the importance of location and convenience, which is impossible for Airbnb hosts to improve, 
but can be partly improved or controlled by peer-to-peer accommodation platforms. Additionally, for culturally different groups, the findings have different implications. Foreign guests care more about homeliness; thus, Airbnb hosts can provide a comfortable and homelike environment to improve guest satisfaction and emphasize such features on their websites to attract the foreign guest. Domestic guests pay more attention to the check-in process and house design and decoration; thus, to improve domestic guests' satisfaction, Airbnb hosts should be more responsive to guests in terms of check-in issues and improving their house design and decoration.

Several limitations should be mentioned, which also provide directions for future research. First, this study selected Beijing, China as a case study to investigate the accommodation experience in the sharing economy, which means that the results are not meant to be generalized to other cities. Second, we only analyzed the online reviews on Airbnb, which means that we could explore other peer-to-peer accommodation platforms like HomeAway. Furthermore, the data was collected from Inside Airbnb website, which may present information of which the public are unable to judge the levels of accuracy. Nevertheless, our assumption would not affect the findings of this study. In the future, datasets from other platforms should also be collected and analyzed. Third, we only examined the Airbnb reviews from two culturally different groups (the domestic Chinese and foreign English-speaking customers). Future studies could also examine reviews in other languages and explore the experiential perception of customers from other cultural backgrounds. Last, the LDA method used in this study assumed there was no correlation between topics, which can be further improved by accounting for correlations between topics with advanced methods.

Author Contributions: Z.Z. provided literature reviews and quantitative analyses. R.J.C.F. guided the project with direction and ideas, added value to methods and recommendations, and edited the manuscript. All authors have read and agreed to the published version of the manuscript.

Funding: This research received no external funding.

Acknowledgments: We appreciate the journal reviewers' feedback.

Conflicts of Interest: The authors declare no conflict of interest.

\section{References}

1. Hamari, J.; Sjöklint, M.; Ukkonen, A. The sharing economy: Why people participate in collaborative consumption. J. Assoc. Inf. Sci. Technol. 2016, 67, 2047-2059. [CrossRef]

2. Zhang, Z.; Fu, R.J.; Han, L.D.; Yang, L. Key Factors Affecting the Price of Airbnb Listings: A Geographically Weighted Approach. Sustainability 2017, 9, 1635. [CrossRef]

3. Airbnb. Fast Facts. Available online: https://press.airbnb.com/fast-facts/ (accessed on 11 June 2019).

4. Lampinen, A.; Cheshire, C. Hosting via Airbnb: Motivations and financial assurances in monetized network hospitality. In Proceedings of the 2016 CHI Conference on Human Factors in Computing Systems, San Jose, CA, USA, 7-12 May 2016; pp. 1669-1680.

5. Guttentag, D. Airbnb: Disruptive innovation and the rise of an informal tourism accommodation sector. Curr. Issues Tour. 2015, 18, 1192-1217. [CrossRef]

6. Meleo, L.; Romolini, A.; De Marco, M. The Sharing Economy Revolution and Peer-to-Peer Online Platforms. The Case of Airbnb; Springer: Cham, Switzerland, 2016; Volume 247, pp. 561-570. [CrossRef]

7. Ert, E.; Fleischer, A.; Magen, N. Trust and reputation in the sharing economy: The role of personal photos in Airbnb. Tour. Manag. 2016, 55, 62-73. [CrossRef]

8. Liang, L.J.; Choi, H.C.; Joppe, M. Understanding repurchase intention of Airbnb consumers: Perceived authenticity, electronic word-of-mouth, and price sensitivity. J. Travel Tour. Mark. 2018, 35, 73-89. [CrossRef]

9. Choi, K.H.; Jung, J.H.; Ryu, S.Y.; Kim, S.D.; Yoon, S.-M. The Relationship between Airbnb and the Hotel Revenue: In the Case of Korea. Indian J. Sci. Technol. 2015, 8, 8. [CrossRef]

10. Zervas, G.; Proserpio, D.; Byers, J.W. The rise of the sharing economy: Estimating the impact of Airbnb on the hotel industry. J. Mark. Res. 2017, 54, 687-705. [CrossRef] 
11. Li, Y.; Pan, Q.; Yang, T.; Guo, L. Reasonable price recommendation on Airbnb using Multi-Scale clustering. In Proceedings of the 2016 35th Chinese Control Conference (CCC), Chengdu, China, 27-29 July 2016; pp. 7038-7041.

12. Wang, D.; Nicolau, J.L. Price determinants of sharing economy based accommodation rental: A study of listings from 33 cities on Airbnb.com. Int. J. Hosp. Manag. 2017, 62, 120-131. [CrossRef]

13. Zhang, Z.; Fu, R.J. Assessing Airbnb Logistics in Cities: Geographic Information System and Convenience Theory. Sustainability 2019, 11, 2462. [CrossRef]

14. Gutiérrez, J.; García-Palomares, J.C.; Romanillos, G.; Salas-Olmedo, M.H. The eruption of Airbnb in tourist cities: Comparing spatial patterns of hotels and peer-to-peer accommodation in Barcelona. Tour. Manag. 2017, 62, 278-291. [CrossRef]

15. Priporas, C.-V.; Stylos, N.; Rahimi, R.; Vedanthachari, L.N. Unraveling the diverse nature of service quality in a sharing economy: A social exchange theory perspective of Airbnb accommodation. Int. J. Contemp. Hosp. Manag. 2017, 29, 2279-2301. [CrossRef]

16. Cheng, M.; Jin, X. What do Airbnb users care about? An analysis of online review comments. Int. J. Hosp. Manag. 2019, 76, 58-70. [CrossRef]

17. Luo, Y.; Tang, R. Understanding hidden dimensions in textual reviews on Airbnb: An application of modified latent aspect rating analysis (LARA). Int. J. Hosp. Manag. 2019, 80, 144-154. [CrossRef]

18. Wang, C.R.; Jeong, M. What makes you choose Airbnb again? An examination of users' perceptions toward the website and their stay. Int. J. Hosp. Manag. 2018, 74, 162-170. [CrossRef]

19. Sthapit, E.; Jiménez-Barreto, J. Exploring tourists' memorable hospitality experiences: An Airbnb perspective. Tour. Manag. Perspect. 2018, 28, 83-92. [CrossRef]

20. Bae, S.J.; Lee, H.; Suh, E.-K.; Suh, K.-S. Shared experience in pretrip and experience sharing in posttrip: A survey of Airbnb users. Inf. Manag. 2017, 54, 714-727. [CrossRef]

21. Mahadevan, R. Examination of motivations and attitudes of peer-to-peer users in the accommodation sharing economy. J. Hosp. Mark. Manag. 2018, 27, 679-692. [CrossRef]

22. Tussyadiah, I. Factors of satisfaction and intention to use peer-to-peer accommodation. Int. J. Hosp. Manag. 2016, 55, 70-80. [CrossRef]

23. Pung, J.M.; Del Chiappa, G.; Sini, L. Booking experiences on sharing economy platforms: An exploration of tourists' motivations and constraints. Curr. Issues Tour. 2019, 1-13. [CrossRef]

24. Mody, M.A.; Suess, C.; Lehto, X. The accommodation experiencescape: A comparative assessment of hotels and Airbnb. Int. J. Contemp. Hosp. Manag. 2017, 29, 2377-2404. [CrossRef]

25. Belarmino, A.; Whalen, E.; Koh, Y.; Bowen, J.T. Comparing guests' key attributes of peer-to-peer accommodations and hotels: Mixed-methods approach. Curr. Issues Tour. 2017, 22, 1-7. [CrossRef]

26. Zhang, G.; Cui, R.; Cheng, M.; Zhang, Q.; Li, Z. A comparison of key attributes between peer-to-peer accommodations and hotels using online reviews. Curr. Issues Tour. 2019, 23, 530-537. [CrossRef]

27. Birinci, H.; Berezina, K.; Cobanoglu, C. Comparing customer perceptions of hotel and peer-to-peer accommodation advantages and disadvantages. Int. J. Contemp. Hosp. Manag. 2018, 30, 1190-1210. [CrossRef]

28. Zhang, G.; Wang, R.; Cheng, M. Peer-to-peer accommodation experience: A Chinese cultural perspective. Tour. Manag. Perspect. 2020, 33, 100621. [CrossRef]

29. Song, H.; Park, J. Experience co-creation in the P2P accommodation sharing sector in China. In CAUTHE 2020: 20: 20 Vision: New Perspectives on the Diversity of Hospitality, Tourism and Events; Auckland University of Technology: Auckland, New Zeeland, 2020; p. 378.

30. Wei, W.; Miao, L.; Huang, Z.J. Customer engagement behaviors and hotel responses. Int. J. Hosp. Manag. 2013, 33, 316-330. [CrossRef]

31. Pullman, M.; McGuire, K.; Cleveland, C. Let me count the words: Quantifying open-ended interactions with guests. Cornell Hotel Restaur. Adm. Q. 2005, 46, 323-343. [CrossRef]

32. Zhou, L.; Ye, S.; Pearce, P.L.; Wu, M.-Y. Refreshing hotel satisfaction studies by reconfiguring customer review data. Int. J. Hosp. Manag. 2014, 38, 1-10. [CrossRef]

33. Barreda, A.; Bilgihan, A. An analysis of user-generated content for hotel experiences. J. Hosp. Tour. Technol. 2013, 4, 263-280. [CrossRef]

34. Brochado, A.; Troilo, M.; Shah, A. Airbnb customer experience: Evidence of convergence across three countries. Ann. Tour. Res. 2017, 63, 210-212. [CrossRef] 
35. Ren, L.; Qiu, H.; Ma, C.; Linc, P. Investigating accommodation experience in budget hotels. Int. J. Contemp. Hosp. Manag. 2018, 30, 2662-2679. [CrossRef]

36. Yang, S.; Huang, S.; Shen, G. Modelling Chinese consumer choice behavior with budget accommodation services. Int. J. Cult. Tour. Hosp. Res. 2017, 11, 341-354. [CrossRef]

37. Blei, D.M.; Ng, A.Y.; Jordan, M.I. Latent dirichlet allocation. J. Mach. Learn. Res. 2003, 3, 993-1022.

Publisher's Note: MDPI stays neutral with regard to jurisdictional claims in published maps and institutional affiliations.

(C) 2020 by the authors. Licensee MDPI, Basel, Switzerland. This article is an open access article distributed under the terms and conditions of the Creative Commons Attribution (CC BY) license (http://creativecommons.org/licenses/by/4.0/). 